\title{
ANATOMICAL VARIATIONS OF SCIATIC NERVE BIFURCATION IN
} HUMAN CADAVERS

\section{Gangulappa ${ }^{1}$, K. Shashi Kantha ${ }^{* 2}$.}

${ }^{1}$ Associate professor, Department of Anatomy, Govt. Medical College, Ananthapuramu, Andhra Pradesh, India.

${ }^{* 2}$ Assistant Professor, Department of Anatomy, Kakatiya Medical College, Warangal, Telangana, India.

\section{ABSTRACT}

Background: the sciatic nerve is largest and thickest nerve in human body. It originates from L4-S3 roots of sacral plexus. It consists of 2 components namely tibial and common peroneal nerves. It passes through greater sciatic foramen and appears in the gluteal region below piriformis muscle, passes along back of the thigh and divides into its terminal branches viz tibial and common peroneal, near the superior angle of popliteal fossa. This point of bifurcation into terminal branches may be variable which might be important for the clinicians.

Aim: studying variations of sciatic nerve bifurcation at different levels

Materials and methods- study conducted on 50 lower limbs, properly embalmed with formalin. The gluteal region dissected and the level of bifurcation of sciatic nerve is recorded.

Results: In $42(84 \%)$ limbs the sciatic nerve terminated at the superior angle of popliteal fossa.3 limbs (6\%) showed high level bifurcation in the pelvis and both branches emerged separately in infra piriform compartment. In 2 limbs (4\%) sciatic nerve divided in the gluteal region. In 3(6\%) limbs sciatic nerve divided in the middle of the thigh.

Conclusion: knowledge of variation of sciatic nerve bifurcation helps the clinicians during intra muscular injections, popliteal and sciatic blocks, hip surgeries.

KEY WORDS: Sciatic Nerve, Bifurcation, Piriformis Muscle.

Address for Correspondence: Dr. K. Shashi Kantha, Assistant Professor, Department of Anatomy, Kakatiya Medical College, Warangal, Telangana, India. E-Mail: shashi.kashojjala@gmail.com

Access this Article online Quick Response code

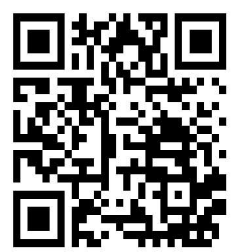

DOI: $10.16965 /$ ijar.2018.339

Journal Information

International Journal of Anatomy and Research

ICV for 2016 ISSN (E) 2321-4287 | ISSN (P) 2321-8967

90.30 https://www.ijmhr.org/ijar.htm

DoI-Prefix: https://dx.doi.org/10.16965/ijar

$(\mathrm{cc}) \mathrm{ET}-\mathrm{NC}-\mathrm{si}$

Article Information

Received: 29 Jul 2018

Peer Review: 29 Jul 2018

Revised: None
Accepted: 06 Sep 2018

Published (O): 10 Oct 2018

Published (P): 10 Oct 2018

\section{INTRODUCTION}

Sciatic is a greek word derived from "Ischiadicus".the sciatic nerve is also known as the ischiadic nerve or ischiatic nerve and it is the largest nerve in the humans and other animals [1]. The sciatic nerve is the nerve of posterior compartment of the thigh and all compartments of the leg and foot. Formed in the pelvis by the ventral rami of $L 4$ to $S 3$, it is $2 \mathrm{~cm}$ in width at its origin and is the thickest nerve in the body. It enters the lower via greater sciatic foramen below piriformis muscle and descends between the greater trochanter and ischialtuberosity. The nerve passes along the back of the thigh, where it is crossed by the long head of biceps femoris and divides into its two components, tibial nerve and common peroneal (fibular)nerve just proximal to knee.

The sciatic nerve supplies the knee flexors and 
all the muscles below the knee. Complete palsy of the nerve causes flail foot and severe difficulty in walking. The nerve is vulnerable in posterior dislocation of hip. External compression over the buttock can injure the nerve. Complete sciatic nerve palsy is rare [2].

\section{MATERIALS AND METHODS}

25 embalmed cadavers of both sexes between the ages of $40-70$ years were dissected in the anatomy dissection hall during routine dissections of I MBBS students in a span of 4 years in Kakatiya Medical College Warangal and Govt. Medical College, Ananthapuramu, Andhra Pradesh, India.

Gluteal regions of 50 lower extremities of 25 embalmed cadavers were dissected by reflecting skin, fat and gluteus maximus. Gluteus maximus muscle is elevated to expose the structure underneath it. Piriformis muscle and the relation of sciatic nerve to the muscle, both the gemelli, obturator internus and quadrates femoris are identified and exposed.

The course of sciatic nerve is studied in detail and the point of bifurcation of sciatic nerve is noted.

\section{OBSERVATIONS AND RESULTS}

25 embalmed cadavers comprising of 50 lower limbs are studied for the anatomical variations in bifurcation of sciatic nerve. Out of 50 limbs we found that in 42 limbs the sciatic nerve has shown normal anatomy where the sciatic nerve exited the pelvis through infra piriform portion of greater sciatic foramen and divided into tibial and common peroneal nerve at the superior angle of poplitealfossa.[figure no 1 and 2]

The rest of 8 limbs showed variation in the level of bifurcation of the sciatic nerve. Out of 8 variants, 3 limbs showed high level bifurcation and tibial and common peroneal nerves are seen emerging out separately under piriformismuscle[fig no3]. In the other 5 limbs the place of division of sciatic nerve is seen at different levels from lower border of gluteus maximus to the middle of thigh(fig 4,5\&6)

In one cadaver the variation of sciatic nerve is seen on both the sides. The left sided limb showed high division and both tibial and common peroneal nerves are seen emerging separately under piriformis. Where as in right limb the division of sciatic nerve occurred in the middle of thigh (fig no 7).

Fig. 1: Showing normal course of Sciatic nerve in glutealregion [PF- Piriformis, SN- Sciatic Nerve] [Courtesy-Dr.TanviMahajan,Dr.BhosgikarAnup, Dr.N.G.Mulimani]

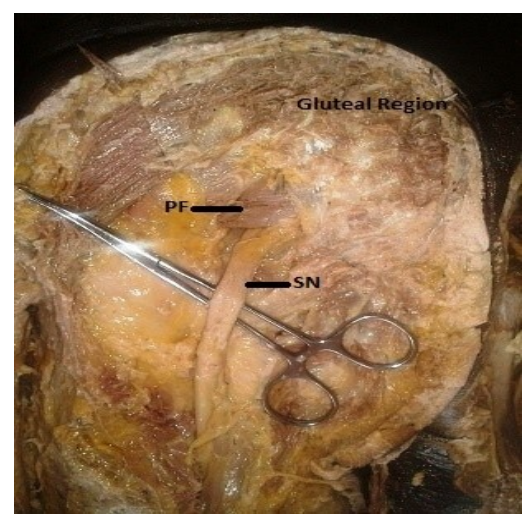

Fig. 2: Division at the level of upper angle of poplitealfossa.

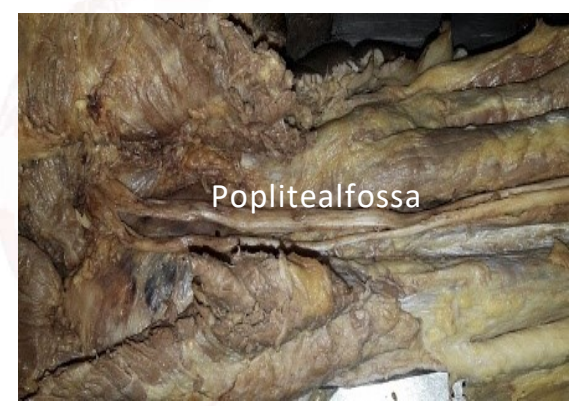

Fig. 3: Division of sciatic nerve at higher level. Both Tibial nerve and Common peroneal nerve are seen separately below piriformis.

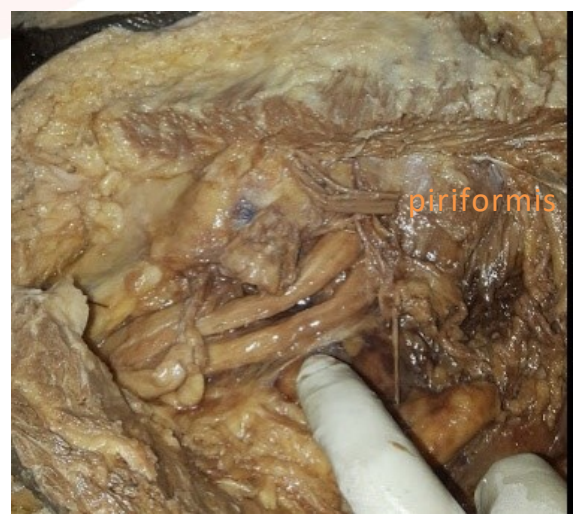

Fig. 4: Division of sciatic nerve at the lower border of gluteus maximus.

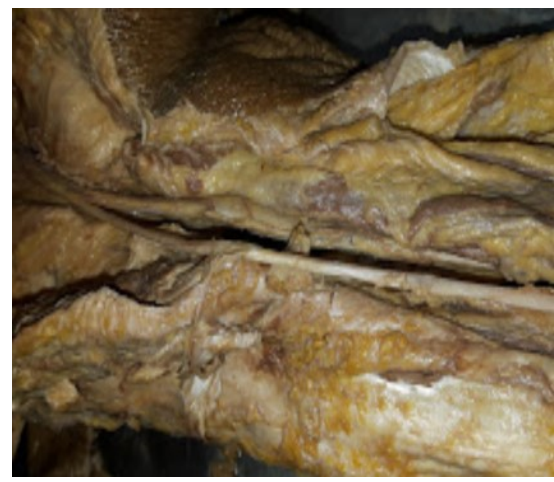


Fig. 5: Division at the lower border of gluteus maximus.

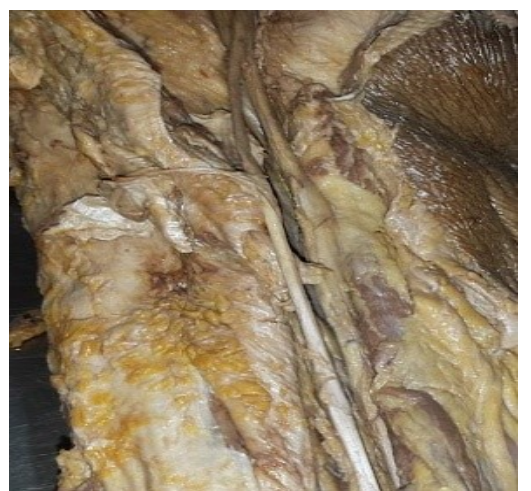

Fig. 6: Division in the middle of thigh.

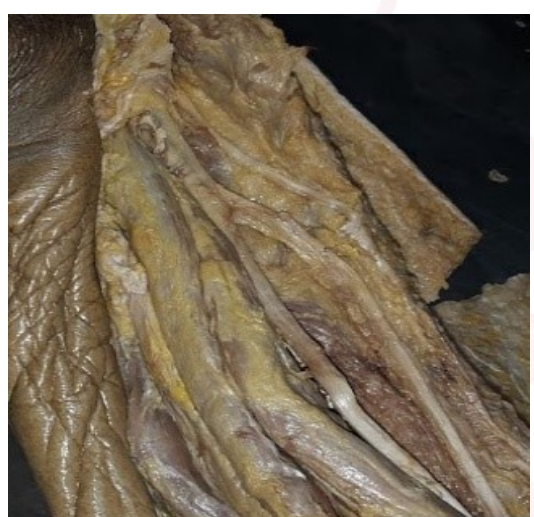

Fig. 7: Bilateral variation of division of sciatic nerve on both sides.

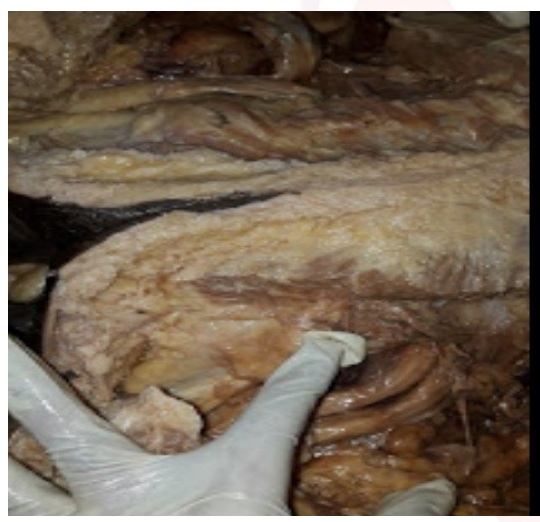

\section{DISCUSSION}

Many variations during the course and distribution of sciatic nerve have been reported. The point of division of the sciatic nerve into its major components (tibial and common fibular) is very variable. The common site is at the junction of the middle and lower thirds of the thigh, near the apex of the poplitealfossa, but the division may occur at any level above this point, and rarely may occur below it.

During embryological development at the base of the limb bud, the nerves contributing to the lower limb form two plexuses (lumbar and sacral). Later, as the elements from each of these plexuses grow out into the limb, they are subdivided into dorsal and ventral components, for the dorsal and ventral musculatures. The sciatic nerve is formed when the large dorsal component of the sacral plexus (common peroneal nerve) and the ventral component (tibial nerve) move downward close together. The two portions of the sciatic nerve develops separately in early embryonic stage and maintain their identity throughout their extension, although joined together to form a single nerve trunk by a common connective tissue sheath [3]. Thus, during the development, the two components of sciatic nerve in the process of unification get wrapped around by a common connective tissue sheath. The level at which common connective tissue wrapping comes to a halt, branching of sciatic nerve into common peroneal and tibial components is seen.

Hence, based on their previously mentioned developmental formation, it is possible that the common peroneal and the tibial divisions of the sciatic nerve separate from each other at different levels from their origins - within pelvis, in the gluteal region, the posterior compartment of the thigh or at the apex of poplitealfossa. Various studies have been reported on the level of sciatic nerve division into tibial and common peroneal nerve.

In this study 50 lower limbs were taken for study to observe the variation in the level of termination of the sciatic nerve. In 42 limbs (84\%) sciatic nerve terminated at the superior angle of poplitealfossa and in 3 limbs (6\%) it terminated in pelvic region and both tibial and common peroneal nerves emerged separately under piriformis. In 2 limbs (4\%) the termination occurred in gluteal region and in 3 limbs $(6 \%)$ the sciatic nerve terminated in the middle of the thigh.

Beaton and Anson observed 120 specimens in 1937 [4] and 240 specimens in 1938 [5] and classified the variations into 6 types.

Tomaszewski et al [6] modified Beaton and Anson's classification and added another group. Type 7.

Beaton and Anson's classification:

Type I-the sciatic nerve passes below the piriformis muscle (most common) 
D. Gangulappa, K. Shashi Kantha. ANATOMICAL VARIATIONS OF SCIATIC NERVE BIFURCATION IN HUMAN CADAVERS.

Type II-the sciatic nerve divides in the pelvis and the common peroneal pierces the piriformis muscle. The tibial nerve passes below the piriformis.

Type III-the sciatic nerves divides in the pelvis, the common peroneal passes above the piriformis whereas the tibial nerve runs below the muscle.

Type IV-the sciatic nerve pierces the piriformis muscle.

Type $\mathbf{V}$-the sciatic nerve divides in the pelvis, the common peroneal runs over the piriformis and tibial nerve pierces the piriformis muscle.

Type $\mathrm{VI}-$ the sciatic nerve exits pelvis above the piriformis muscle.

Type VII-( Tomaszewski) the sciatic nerve divides in the pelvis and the common peroneal and tibial exit separately below the piriformis muscle.

In our study we observed type I category in 42 specimens (84\%). Type II to Type VI of Beaton and Anson's classification are not found. Type VII (Tomaszewski) is found in 3(6\%) specimens.

Mengistu Desalegm et al [7]. In their study in Ethiopia has observed 3 types of courses of sciatic nerve. These are -

Type I- undivided sciatic nerve passes below piriformis (92\%)

Type II-divided sciatic nerve passes above and below the piriformis muscle (55\%).

Type III - divided sciatic nerve emerges below piriformis muscle

Ugrenovic et al have found high division of sciatic nerve in $27.5 \%$ of specimens in a study performed on 100 fetuses [8]. Dr. Satyajit Sangram et al [9] studied 50 inferior extremities of 25 cadavers, in 9 lower limbs sciatic nerve divided high above into tibial and common peroneal nerves. In seven of these specimens $(14 \%)$, the nerve bifurcates in pelvic cavity and emerges into gluteal region below the lower border of piriformis muscle separately.

Yousuf saleem khan et al reported a case in which , sciatic nerve is divided into tibial and common peroneal nerves within pelvis and enteres into gluteal region below the piriformis muscle [10]. Saritha. $S$ et al studied 50 gluteal regions and found that in one specimen on the left side sciatic nerve divided in pelvis and both tibial and common peroneal nerves emerge out below the piriformis [1].

Shastrakar et al reported that in $20 \%$ of specimens sciatic nerve bifurcation is in pelvic region, both tibial and common peroneal nerves passes through infra piriformis portion of greater sciatic foramen in different sheaths [11].

Patel et al reported that in $9.09 \%$ cases sciatic nerve divides in pelvis and the tibial and the common peroneal nerves course separately below the piriformis [12].

A.D. Shewale et al observed 90 specimens out of which 10 specimens $(11.11 \%)$ showed that both common peroneal and tibial nerves were emerging from infra Piriform compartment. In 10 specimens $(11.11 \%)$ sciatic nerve terminated in gluteal region. In 4 specimens (4.44\%)sciat nerve terminated in middle of thigh [13].

Mengstu Desalegn Kiros et al observed 50 lower limbs and found that in 4 limbs (8\%) the sciatic nerve is divided in pelvic region, in 2 limbs (4\%) in gluteal region and in 2 limbs (4\%) the division occurred at the middle part of back of thigh [14].

Ogeng $\mathrm{O} J \mathrm{~A}$ et al observed 164 cases among these, in $16(9.8 \%)$ sciatic nerve divides proximal to the piriformis in the pelvis and emerges out of pelvis below the piriformisseperately as tibial and common peroneal branches. In $17(10.4 \%)$ cases bifurcation of sciatic nerve is found in the middle of thigh and in 4 cases (2.4\%) bifurcation occurred in glutealregion [15].

Sabanis A.S et al observed 140 lower limbs of 70 cadavers. In 10 (7\%) high bifurcation of sciatic nerve is found below the piriformismuscle [16]. Bhattacharya et al on right lower limb where sciatic nerve dividedinthe gluteal region after emerging from the lower border of piriformismuscle [17].

Dupin A.B.F et al reported a case in left gluteal region where a high division of sciatic nerve is noted passing through the greater sciatic foramen beneath the inferior border of Piriformis muscle [18].

MohdSalahuddinAnsari et al carried out a study on 30 lower limbs of human cadavers an found that in $43 \%$ the division of sciatic nerve was just below the lower border of piriformis muscle and 
in $14 \%$ it is near middle of thigh [19].

Peter EtinEkanen et al reported a case where, the sciatic nerve bifurcates into common peroneal and tibial nerves in the gluteal region just below the piriformismuscle [20]. Sanjay Kumar Yadav et al studied 42 limbs, within them 8 specimens(19.04\%) showed sciatic nerve bifurcation below piriformis muscle and 6 cases(14.28\%) showed the bifurcation in the middle of thigh [21].

BirhaneAlemBerihu et al used 56 limbs for study, in which 6(10.7\%) lower limbs showed bifurcation of sciatic nerve below the piriformis [22]. Prakash et al observed that $16.3 \%$ of specimens have bifurcation of sciatic nerve in the glutealregion [23].

Gurvencer $M$ et alexamined 50 gluteal regions, in 26 gluteal regions(52\%) sciatic nerve exited the as an undivided,in 24 specimens (48\%) sciatic nerve divided in the pelvis.thetibial nerve and common peroneal nerve leave the pelvis through the infrapiriform portion of greater sciatic foramen together with in different sheath [24].

Muthukumar et al carried a cadaveric study of sciatic nerve and its level of bifurcation in 50 lower limbs and observed that the division of sciatic nerve in the middle of the thigh in $38 \%$ specimens and in the poplitealfossa in $32 \%$ specimens [25].

\section{CONCLUSION}

In our study, majority of sciatic nerve terminations were observed in the superior angle of poplitealfossa, but few variations were observed where in the high divisions of sciatic nerve occurred. The variant terminations of sciatic nerve were observed at different levels viz, high in pelvis, in gluteal region and in thigh. These variations of sciatic nerve have clinical implications regarding deep intramuscular injections, popliteal block, sciatic nerve block, hip surgery and neurology.

High division of sciatic nerve results in piriformis syndrome, sciatica, Failed sciatic nerve block in anesthesia, nerve injury during deep intramuscular injections. Compression of sciatic nerve any where during its course may contribute to clinical conditions like sciatica and piriformis syndrome. Entrapment of the nerve within the piriformis muscle is one of the reasons of its compression, the condition being called 'pyriformis syndrome'. Pyriformis syndrome clinical symptoms are similar to inter vertebral disc herniation in which patients suffer from low back ache, buttock and posterior thigh pain showing occasional neurological symptoms such as foot drop and dysesthesia [26].

During the sciatic nerve block, the local anesthetic medication is infiltrated into the connective sheath around the nerve. Complete sciatic nerve blockage does not occur if the sciatic nerve is present as separately sheathed bundles up to the lower gluteal level. This condition, if present, may lead to the failure of sciatic nerve block even after multiple punctures and attempts [27].

Thus the awareness about these variations of sciatic nerve is important for surgeons, anaesthetists, radiologists and clinicians during diagnosis of various clinical conditions.

\section{Conflicts of Interests: None}

\section{REFERENCES}

[1]. Saritha et al .anatomical variations in the bifurcation of sciatic nerve . a cadaveric study and its clinical implications, anatomy and Physiology 2012;2(5):1-4.

[2]. Susan standring . Gray's Anatomy 39th Edition. The Anatomical Basis of Clinical Practise 2005: pp 1403-04 \&1456.

[3]. Babinski MA, Machado FA, Costa WS. A rare variation in the high division of the sciatic nerve surrounding the superior gemellus muscle. European journal of Morphology. 2003;41(1):41-2.

[4]. Beaton L.E., Anson B., The relation of the sciatic nerve and its subdivisions to the Piriformis muscle. AnatRec 1937;70:1-5.

[5]. Beaton L.E :The sciatic nerve and piriformismuscle : Their inter relations possible cause of coccodynia: J bone joint surg Am 1938;20:686-688.

[6]. Tomaszewski et al : The surgical anatomy of sciatic nerve : A meta analysis. J orthop Res do I : 10, 1002/ Jor- 23186:2016.

[7]. Mengstu Desalegn et al; Variations of sciatic nerve its exit in relation to Piriformis muscle in the North Ethopia. International journal of Pharma sciences and research. 2014;5(12):953-956.

[8]. Ugrenovic et al: the level of sciatic nerve division and its relation to the piriformis muscle. VoJnosant: Pregl 2005;62(1):45-49. 
[9]. Dr. Satyajit Sangram et al; A study on the bifurcation of sciatic nerve with its clinical significance: Indian journal of basic and applied medical research(IJBAMR). june 2015;4(3):34-44.

[10]. Yusuf Saleem Khan et al. A rare case of bilateral high division of sciatic nerve with unilateral divided piriformis and unusual high origin of genicular branch of common fibular nerve. International Journal of anatomical variations 2011;4:63-66.

[11]. Shastrakar et:al Study of variation in the high division of sciatic nerve and its relationship with the piriformismuscle: Med Res Chron 2015;2(3):359365.

[12]. Patel S. et al : A variation in the high division of the sciatic nerve and its relation with piriformis muscle. National J Med Res 2011;1(2).

[13]. A D. Shewale et al: Study of variation in the divisions course and termination of the sciatic nerve: JKIMSU 2013;2(1):62-68.

[14]. Mengstu Desalegn Kiros et al: Anatomical variation in the level of bifurcation of the sciatic nerve in ethopia: Journal of experimental and clinical anatomy $2015 ; 14(1): 1-4$.

[15]. Ogeng'O JA et al: variant Anatomy of sciatic nerve in black Kenyan population. Folia morphol 2001;70(3):175- 179.

[16]. Sabnis AS et al : Anatomical Variation of sciatic nerve bifurcation in human cadavers. Journal of clinical research letters, 2012;3(2):46-48.

[17]. Bhattacharya $S$ et al : Different neuro muscular variation in the Gluteal region. Int Jour AnatVar (IJAV) 2013;6:136-139.

[18]. Dupin A.B.F et al: High division ofSciatic nerve associated with a double superior gamellus muscle. J.Morphol . Sci. 2017;34(3):134-136.

[19]. Mohd Salahuddin Ansari et al: Anatomical Variations in the division and innervations of the sciatic nerve with its clinical consequences. International Journal of Anatomy, Radiology and Surgery.2016; 5(3):Ao22-Ao25.
[20]. Peter EtinEkanem et al: Variation of Sciatic nerve bifurcation in dissected cadavers from ethopia and the clinical implications- A case report. Int J Anat Res 2015;3(3):1341-44.

[21]. Sanjay Kumar Yadav et al: Anatomical study of sciatic nerve and its variation. A cadaveric study in northern Karnataka region-Int J Bio Med Res: 2015;6(4):5267-5271.

[22]. BirhaneAlemBerihu et al: Anatomical Variation in bifurcation and trifurcation of sciatic nerve and its implications in selected university in ethopia: Bio Med Control Research Notes 2015:8(633):1-7.

[23]. Prakash et al: Variation in the high division of the sciatic nerve and relationship between the sciatic nerve and piriformis. Singapore Med J 2010;51(9):721.

[24]. Guvencer $M$ et at: Variation in the high division of sciatic nerve and relationship between sciatic nerve and piriformis. Turk NuroSurg 2009;19(2):139-144.

[25]. Muthu Kumar et al; A Cadaveric study of scitic nerve and its level of bifurcation: Journal of Clinical and Diagnostic Research 2011;5(8):1502-04.

[26]. Parziale JR et al The piriformis muscle syndrome AM.J 1996;25:819-823.

[27]. Ronald D. Miller, Edited Miller's Anesthesia Volume 2; 7th edition; Churchill Livingstone Elsevier 2010; pp-1659.

How to cite this article:

D. Gangulappa, K. Shashi Kantha. ANATOMICAL VARIATIONS OF SCIATIC NERVE BIFURCATION IN HUMAN CADAVERS. Int J Anat Res 2018;6(4.1):5772-5777. DOI: 10.16965/ijar.2018.339 